\title{
Neutrophil-to-lymphocyte ratio and incident end-stage renal disease in Chinese patients with chronic kidney disease: results from the Chinese Cohort Study of Chronic Kidney Disease (C-STRIDE)
}

Qiongjing Yuan ${ }^{1}$, Jinwei Wang ${ }^{2}$, Zhangzhe Peng ${ }^{1}$, Qiaoling Zhou ${ }^{1}$, Xiangcheng Xiao ${ }^{1}$, Yanyun Xie ${ }^{1}$, Wei Wang ${ }^{1}$, Ling Huang ${ }^{1}$, Wenbin Tang ${ }^{1}$, Danni Sun ${ }^{1}$, Luxia Zhang ${ }^{2,3}$, Fang Wang ${ }^{2}$, Ming-Hui Zhao ${ }^{2,4}$, Lijian Tao ${ }^{1}$, Kevin He ${ }^{5}$, Hui $\mathrm{Xu}^{1 *}$ and C-STRIDE study group

\begin{abstract}
Background: Chronic kidney disease (CKD) leads to end-stage renal failure and cardiovascular events. An attribute to these progressions is abnormalities in inflammation, which can be evaluated using the neutrophil-to-lymphocyte ratio (NLR). We aimed to investigate the association of NLR with the progression of end stage of renal disease (ESRD), cardiovascular disease (CVD) and all-cause mortality in Chinese patients with stages 1-4 CKD.
\end{abstract}

Methods: Patients with stages 1-4 CKD (18-74 years of age) were recruited at 39 centers in 28 cities across 22 provinces in China since 2011. A total of 938 patients with complete NLR and other relevant clinical variables were included in the current analysis. Cox regression analysis was used to estimate the association between NLR and the outcomes including ESRD, CVD events or all-cause mortality.

Results: Baseline NLR was related to age, hypertension, serum triglycerides, total serum cholesterol, CVD history, urine albumin to creatinine ratio (ACR), chronic kidney disease-mineral and bone disorder (CKD-MBD), hyperlipidemia rate, diabetes, and estimated glomerular filtration rate (eGFR). The study duration was 4.55 years (IQR 3.52-5.28). Cox regression analysis revealed an association of NLR and the risk of ESRD only in patients with stage 4 CKD. We did not observe any significant associations between abnormal NLR and the risk of either CVD or all-cause mortality in CKD patients in general and CKD patients grouped according to the disease stages in particular.

Conclusion: Our results suggest that NLR is associated with the risk of ESRD in Chinese patients with stage 4 CKD. NLR can be used in risk assessment for ESRD among patients with advanced CKD; this application is appealing considering NLR being a routine test.

Trial registration ClinicalTrials.gov Identifier NCT03041987. Registered January 1, 2012. (retrospectively registered) (https://www.clinicaltrials.gov/ct2/show/NCT03041987?term=Chinese+Cohort+Study+of+Chronic+Kidney+Disea se+\%28C-STRIDE\%29\&rank=1)

Keywords: Neutrophil-to-lymphocyte ratio (NLR), Chronic kidney disease (CKD), End stage of renal disease (ESRD)

\footnotetext{
${ }^{*}$ Correspondence: xuhuiye@csu.edu.cn

${ }^{1}$ Department of Nephrology, Xiangya Hospital, Central South University,

87 Xiangya Road, Changsha 410008, Hunan, China

Full list of author information is available at the end of the article
} 


\section{Background}

Chronic kidney disease (CKD) is a growing health problem with an estimated prevalence of $10.8-16 \%$ in major developed and developing countries [1, 2]. Individuals with CKD are at risk of progressive kidney failure, cardiovascular events, and death [3, 4].

Nonmicrobial inflammation contributes to CKD progression and fibrosis [5]. The neutrophil count reflects inflammation, while the lymphocyte count indicates the status of general stress and nutrition. The neutrophilto-lymphocyte ratio (NLR) in CKD patients provides information on the inflammation status [6]. It is suggested that NLR is a complementary prognostic marker for evaluating the cardiovascular risk in CKD3-5 patients [6]. Studies demonstrated that an increase in neutrophil count coupled with a reduction in lymphocyte counts predicts mortality in hemodialysis patients [7] and peritoneal dialysis patient [8]. Also, NLR indicates the rate of stage 4 chronic kidney disease progressing to dialysis [9]. Nevertheless, studies of NLR for its prognosis potential towards ESRD, CVD and all-cause mortality in patients with stage 1-4 CKD other than stage 5 CKD are rare. Since NLR is readily derived from complete blood count tests, its potential as a predictor should be investigated in a large cohort of patients with stage 1-4 CKD.

The objective of this study was to evaluate whether NLR, a simple marker of chronic systemic inflammation, predicts the progression of ESRD, CVD and allcause mortality among CKD1-4 patients in the Chinese Cohort Study of Chronic Kidney Disease (C-STRIDE), the first national prospective CKD cohort of the Chinese population.

\section{Materials and methods}

The design, methods, and baseline characteristics of the Chinese Cohort Study of Chronic Kidney Disease (C-STRIDE) study population has been published; this is a prospective investigation involving 39 clinical centers in 28 cities of 22 provinces in China [10]. The design of C-STRIDE has been described in detail elsewhere [11]. A total of 3358 participants were included until December 31, 2017 after exclusion of patients with missing value of key demographic variables (including blood routine and blood lipid) or loss of follow-up. Of these 3358 participants, 938 patients have NLR and other relevant clinical variables and were used in the current analysis. The C-STRIDE study was approved by the ethics committee of Peking University First Hospital and was in adherence with the Declaration of Helsinki. All participants have consented this study. During the study visit, all C-STRIDE study data were collected by trained staff according to the study protocol [12]. Data were obtained by questionnaires, anthropometric measurements, collection of blood and urine specimens. The albumin/creatinine ratio (ACR) stage was categorized according to an analysis of a spot urine sample: A1 (normoalbuminuria), $\mathrm{ACR}<30 \mathrm{mg} / \mathrm{g}$ creatinine; A2 (microalbuminuria), $30 \leq \mathrm{ACR}<300 \mathrm{mg} / \mathrm{g}$ creatinine; or A3 (macroalbuminuria), ACR $\geq 300 \mathrm{mg} / \mathrm{g}$ creatinine. GFR was estimated from serum creatinine measurements and demographic characteristics by the Chronic Kidney Disease Epidemiology Collaboration (CKD-EPI) equation [1, 13]. Smoking was defined as currently smoking or had ever smoked. Alcohol consumption was defined as a habitual drinker (drink once a day or more). Hypertension was defined as a systolic blood pressure (BP) $\geq 140 \mathrm{mmHg}$ and/or a diastolic $\mathrm{BP} \geq 90 \mathrm{mmHg}$, or a self-reported history of hypertension. Levels of hemoglobin, NLR, fasting blood glucose, serum triglycerides, total cholesterol, LDL-cholesterol, HDL cholesterol, uric acid, serum phosphate, serum calcium, hs-CRP, iPTH, HbA1c, were documented. Plain lateral abdominal x-ray film showed abdominal aortic calcification. CKD-MBD was defined as a triad of interrelated abnormalities of serum biochemistry (serum phosphate levels $>1.49 \mathrm{mmol} / \mathrm{L}$ or $<0.87 \mathrm{mmol} / \mathrm{L}$; serum calcium levels $>2.57 \mathrm{mmol} / \mathrm{L}$ or $<2.1 \mathrm{mmol} / \mathrm{L}$, and iPTH $>70 \mathrm{pg} / \mathrm{mL}$ or $<35 \mathrm{pg} / \mathrm{mL}$ ); or calcification of lateral abdominal $x$-ray film. Patients were considered to have diabetes mellitus if they had a fasting glucose $\geq 7.0 \mathrm{mmol} / \mathrm{L}$; an $\mathrm{HbA} 1 \mathrm{c} \geq 6.5 \%$; took insulin or other anti-diabetic medications; or reported a history of diabetes. CVD history was defined as the past occurrence of a myocardial infarction, admittance into a hospital for congestive heart failure, or severe cardiac arrhythmia incidents (resuscitated cardiac arrest, ventricular fibrillation, sustained ventricular tachycardia, paroxysmal ventricular tachycardia, atrial fibrillation or flutter, severe bradycardia, or heart block). Hyperlipidemia was defined as total cholesterol level $\geq 5.7 \mathrm{mmol} / \mathrm{L}$ or an LDL-cholesterol level $\geq 3.6 \mathrm{mmol} / \mathrm{L}$. Hyperuricemia was defined as a serum concentration of uric acid $\geq 420 \mu \mathrm{mol} / \mathrm{L}$ for men and $\geq 360 \mu \mathrm{mol} / \mathrm{L}$ for women. The abnormal of hsCRP was $\geq 3 \mathrm{mg} / \mathrm{dL}$ [14]. The kidney disease outcomes evaluated in this paper are three facets: (1) ESRD that was defined as progression to hemodialysis, peritoneal dialysis or renal transplantation; (2) CVD risk that was evaluated based on onset of CVD events (myocardial infarction, heart failure, arrhythmia and cerebrovascular disease and peripheral arterial disease) and (3) all-cause mortality (deaths). Doctors at the clinical centers were requested to submit related clinical data to Renal Institute of Peking University. All events were adjudicated by an independent committee consisting of specialists. 


\section{Statistical analyses}

Demographic information and other baseline variables were described using mean \pm SD or median and interquartile range for continuous variables and frequency and proportion for categorical variables. Chi-square or Fisher's exact test was used for comparison of categorical variables between groups, while Mann-Whitney U test or unpaired Student's t test was used for continuous variables. We identified the cutoff point for NLR level using maximally selected log-rank statistics. Prevalence of events according to NLR categorical variables and estimate survival time for each category are calculated with Kaplan-Meier Survival and time-to-event analysis of outcomes were performed using Cox proportional hazards model, including adjustment for potential confounding factors. Covariates for the models were selected based on prior knowledge about the factors that could be potential confounders of the associations of NLR with ESRD. The potential confounders including age (continuous), gender (male vs. female), smoking (yes vs. no), drinking more than once a day (yes vs. no), clinical characteristics [hypertension (yes vs. no), CKD-MBD (yes vs. no), diabetes (yes vs. no), CVD (yes vs. no), hyperlipidaemia (yes vs. no), hyperuricemia (yes vs. no)], hemoglobin (continuous), eGFR (continuous), ACR categories (A1, A2, A3). A $p$ value $<0.05$ was regarded as statistically significant. Proportional hazards assumptions were verified by testing the interaction with time using the likelihood ratio test, which yielded non-significant $p$ values. The results are presented as hazard ratios (HRs) with $95 \%$ confidence intervals (CIs). $p$ values for trend were given by treating dichotomy NLR as a continuous variable. We hypothesized that the effect of NLR might be modified by the CKD stage. The interaction terms were generated between NLR and each of the eGFR levels (CKD1-2 vs. all others, CKD3 vs. all others, CKD4 vs. all others). A stratified analysis in the prediction of ESRD events was conducted by the stages of CKD. A series of sequential models were fit to evaluate the effect of adding certain sets of covariates. All statistical analyses were performed using SPSS 24.0 for Windows (SPSS Inc., Chicago, IL, USA).

\section{Results}

\section{Baseline characteristics of the patients}

Among the total 938 CKD patients from C-STRIDE, the median follow-up time for the adverse outcomes was 4.55 (IQR 3.52-5.28) years. Baseline characteristics of the study population are described in Table 1 . The mean age of the study population was 52.8 years; $58 \%$ of patients were male. $34.2 \%$ of patients were reported ever smoking and $21 \%$ of patients were documented drinking $\geq 1$ times per day. At the baseline, $360(38.4 \%)$ patients had an eGFR greater than $60 \mathrm{~mL} / \mathrm{min} 1.73 \mathrm{~m}^{-2} ; 345(36.8 \%)$, and $233(24.8 \%)$ patients were in CKD stage 3 and 4, respectively. Baseline demographics and biochemical measurements of CKD patients according to dichotomy of baseline NLR are summarized in Table 1. Higher baseline NLR levels were associated with older age, higher blood pressure, hyperlipidaemia, CVD, CKD-MBD, diabetes, but lower levels of eGFR. The cutoff point for the serum NLR level for renal replacement progression was 2.09 (Fig. 1). We also compare the baseline characteristics of 2420 patients without record of NLR in 3359 participants to those who has the record of NLR (Additional file 1: Table S1). There are differences in ever smoking, BMI category, hypertension, uric acid, serum triglycerides, hyperuricemia, LDL cholesterol, HDL cholesterol, hyperlipidaemia, serum phosphorus (sP), $\mathrm{HCO}^{3-}$ and eGFR between NLR group and non-NLR group, but there are no difference in age, sex, drinking, HGB, total serum cholesterol, cardiovascular disease (CVD), ACR, serum calcium (sCa) and diabetes.

\section{The incidence rates of ESRD other than CVD and all-cause mortality events were associated with NLR}

The incidence rates of ESRD, CVD and all-cause mortality events according to binary of NLR levels are shown in Table 2. During the median follow-up of 4.55 (IQR 3.525.28 ) years, there were 123 ESRD events occurred. ESRD rates were 3.14 per 100 person-years. Higher incidence rate of ESRD events was observed with increases in NLR (Fig. 2, $p$ for log-rank test $<0.001$ ). There were 57 CVD and 43 all-cause mortality events; the occurance of both events was not associated with NLR levels (Table 2). Furthermore, we did not detect any significant correlations among hsCRP, another marker of inflammation, with allcause mortality rates, ESRD rates and CVD events (Additional file 1: Table S2).

\section{Associations between NLR and ESRD}

The associations between NLR and ESRD are shown in Table 3. After adjustment for demographic and traditional ESRD risk factors, as well as the baseline eGFR categories and ACR, baseline NLR was independently associated with the occurrence of ESRD in CKD stage 4 patients, with an HR value 2.12 (95\% CI 1.10-4.10) compared with the lower NLR $(p=0.025)$.

\section{Discussion}

The current study suggests that baseline NLR is associated with an increased risk of ESRD in pre-dialysis patients with stage 4 CKD; the association was independent of traditional risk factors of CKD including ACR and eGFR. 
Table 1 Baseline demographic characteristics of participants of C-STRIDE Study according to NLR

\begin{tabular}{|c|c|c|c|c|}
\hline Variable & Total $(n=938)$ & $N L R \geq 2.09(n=520)$ & $N L R<2.09(n=418)$ & $p$ value \\
\hline Age (year)* & $52.8(14.14)$ & $54.0(14.48)$ & $51.3(13.58)$ & $0.047^{* *}$ \\
\hline Sex $(m e n)^{\xi}$ & $544(58.00 \%)$ & $304(58.46 \%)$ & $240(57.42 \%)$ & 0.747 \\
\hline Ever smoking ${ }^{\$}$ & $311(34.2 \%)$ & $180(35.7 \%)$ & $131(32.3 \%)$ & 0.276 \\
\hline Drinking $\geq 1$ times per day $y^{\$}$ & $189(21.00 \%)$ & $101(20.2 \%)$ & $88(22.0 \%)$ & 0.510 \\
\hline BMI category $\left(\mathrm{kg} / \mathrm{m}^{2}\right)^{\#}$ & $24.61(22.04-27.34)$ & $24.61(22.01-27.42)$ & $24.59(21.99-27.31)$ & 0.944 \\
\hline $\mathrm{HGB}(\mathrm{g} / \mathrm{L})^{*}$ & $129.2(22.78)$ & $125.7(23.00)$ & $133.70(21.71)$ & 0.183 \\
\hline Systolic blood pressure $(\mathrm{mmHg})^{*}$ & $127.51(16.71)$ & $129.91(17.88)$ & $124.92(14.96)$ & 0.537 \\
\hline Diastolic blood pressure $(\mathrm{mmHg})^{*}$ & $80.13(10.48)$ & $81.11(11.01)$ & 79.08 (9.78) & 0.918 \\
\hline $\begin{array}{l}\text { Antihypertensive medications token in } \\
2 \text { weeks }\end{array}$ & $507(69.5 \%)$ & $288(74.0 \%)$ & $219(64.4 \%)$ & $0.005^{* *}$ \\
\hline Hypertension $\$$ & $538(57.4 \%)$ & $303(58.3 \%)$ & $235(56.2 \%)$ & $<0.001^{* *}$ \\
\hline Uric acid $(\mu \mathrm{mol} / \mathrm{L})^{*}$ & 373.59 (132.08) & $376.59(136.42)$ & $369.87(126.55)$ & 0.208 \\
\hline Serum triglycerides $(\mathrm{mmol} / \mathrm{L})^{\#}$ & $1.66(1.18-2.39)$ & $1.61(1.13-2.26)$ & $1.79(1.21-2.59)$ & $0.021^{* *}$ \\
\hline Hyperuricemia\$ & $407(44.3 \%)$ & $235(46.2 \%)$ & $172(42.0 \%)$ & 0.201 \\
\hline Total serum cholesterol $(\mathrm{mmol} / \mathrm{L})^{\#}$ & $4.70(4.01-5.57)$ & $4.59(3.94-5.39)$ & $4.82(4.12-5.89)$ & $0.003^{* *}$ \\
\hline LDL cholesterol $(\mathrm{mmol} / \mathrm{L})^{\#}$ & $2.73(2.22-3.40)$ & $2.72(2.20-3.36)$ & $2.74(2.23-3.48)$ & 0.369 \\
\hline $\mathrm{HDL}$ cholesterol $(\mathrm{mmol} / \mathrm{L})^{\#}$ & $1.12(0.91-1.34)$ & $1.12(0.93-1.34)$ & $1.12(0.89-1.34)$ & 0.729 \\
\hline Hyperlipidaemia & $194(26.6 \%)$ & $98(23.7 \%)$ & $96(30.5 \%)$ & $0.039^{* *}$ \\
\hline Cardiovascular disease $\mathrm{s}^{\xi}$ & $124(13.40 \%)$ & $81(15.80 \%)$ & $43(10.40 \%)$ & $0.017^{* *}$ \\
\hline ACR (mg/g creatinine) $)^{\#}$ & $343.05(75.60-780.51)$ & $420.50(112.11-312.90)$ & $290.01(48.20-666.86)$ & $0.000^{* *}$ \\
\hline ACR group $\$$ & 814 & 447 & 367 & $0.006^{* *}$ \\
\hline $1<30 \mathrm{mg} / \mathrm{g}$ & $127(15.6 \%)$ & $56(12.5 \%)$ & $71(19.3 \%)$ & \\
\hline $2=30-299 \mathrm{mg} / \mathrm{g}$ & $248(30.5 \%)$ & $130(29.1 \%)$ & $118(32.2 \%)$ & \\
\hline $3 \geq 300 \mathrm{mg} / \mathrm{g}$ & $439(53.9 \%)$ & $261(58.4 \%)$ & $178(48.5 \%)$ & \\
\hline $\mathrm{sCa}(\mathrm{mmol} / \mathrm{L})^{*}$ & $2.22(0.18)$ & $2.23(0.18)$ & $2.22(0.18)$ & 0.735 \\
\hline $\mathrm{sP}(\mathrm{mmol} / \mathrm{L})^{\#}$ & $1.17(1.05-1.31)$ & $1.17(1.04-1.31)$ & $1.18(1.05-1.32)$ & 0.925 \\
\hline CKD-MBD & $467(54.6 \%)$ & $274(58.1 \%)$ & $193(50.3 \%)$ & $0.023^{* *}$ \\
\hline $\mathrm{HCO}^{3-}(\mathrm{mmol} / \mathrm{L})^{*}$ & $25.70(3.78)$ & 25.54 (3.99) & $25.91(3.49)$ & 0.060 \\
\hline Diabetes $^{\lessgtr}$ & $200(23.8 \%)$ & $135(29.4 \%)$ & $65(17.1 \%)$ & $0.000^{* *}$ \\
\hline $\mathrm{eGFR}\left(\mathrm{mL} / \mathrm{min} / 1.7 \mathrm{~m}^{2}\right)^{*}$ & $57.22(32.67)$ & $48.73(29.63)$ & $67.78(33.24)$ & $0.000^{* *}$ \\
\hline eGFR group $\$$ & 938 & & & \\
\hline$\geq 60 \mathrm{~mL} / \mathrm{min} / 1.73 \mathrm{~m}^{2}$ & $360(38.4 \%)$ & $139(26.7 \%)$ & $221(52.9 \%)$ & $0.000^{* *}$ \\
\hline $30-60 \mathrm{~mL} / \mathrm{min} / 1.73 \mathrm{~m}^{2}$ & $345(36.8 \%)$ & $212(40.8 \%)$ & $133(31.8 \%)$ & \\
\hline $15-30 \mathrm{~mL} / \mathrm{min} / 1.73 \mathrm{~m}^{2}$ & $233(24.8 \%)$ & $169(32.5 \%)$ & $64(15.3 \%)$ & \\
\hline High hs-CRP & $146(15.6 \%)$ & $88(16.9 \%)$ & $58(13.9 \%)$ & 0.414 \\
\hline
\end{tabular}

The number of missing values for each variable: NLR 0 , age 0 , eGFR 0 , sex 0 , education 31 , ever smoking 51 , drinking $\geq 1$ times per day 60 , BMI category 211 , anemia 0 , systolic blood pressure 186, diatolic blood pressure 186, antihypertensive medications token in 2 weeks 334, uric acid 30, total serum cholesterol 338 , serum triglycerides 347, LDL cholesterol 428, HDL cholesterol 425, CKD-MBD 0, cardiovascular disease 28, ACR 149, metabolic acidosis 589, pathogenesis chronic 0, high Hs-CRP 668

The denominator of percentage is number of the variable

* The variable is numerical and statistics is mean (standard deviation), p-value calculated based on T test

\# The variable is numerical and statistics is Median (Interquartile range), p-value calculated based on Wilcoxon test

$\$$ The variable is character and statistics is frequency (percentage), $p$-value calculated based on Chi-square test

** Statistically significant at 0.05

In CKD patients, declines in glomerular filtration rate are associated with increases in the risk of CVD and rapid progression of CKD to end-stage renal disease and mortality $[15,16]$. CKD is a chronic inflammatory condition and remains a substantial economic burden on the patient, caregiver and society [17]. Inflammation is one of the most important initiators of progressive tubule-interstitial fibrosis, which usually culminates in ESRD [18]. Several studies have reported that inflammation plays a role in the decline of kidney function [19]. 

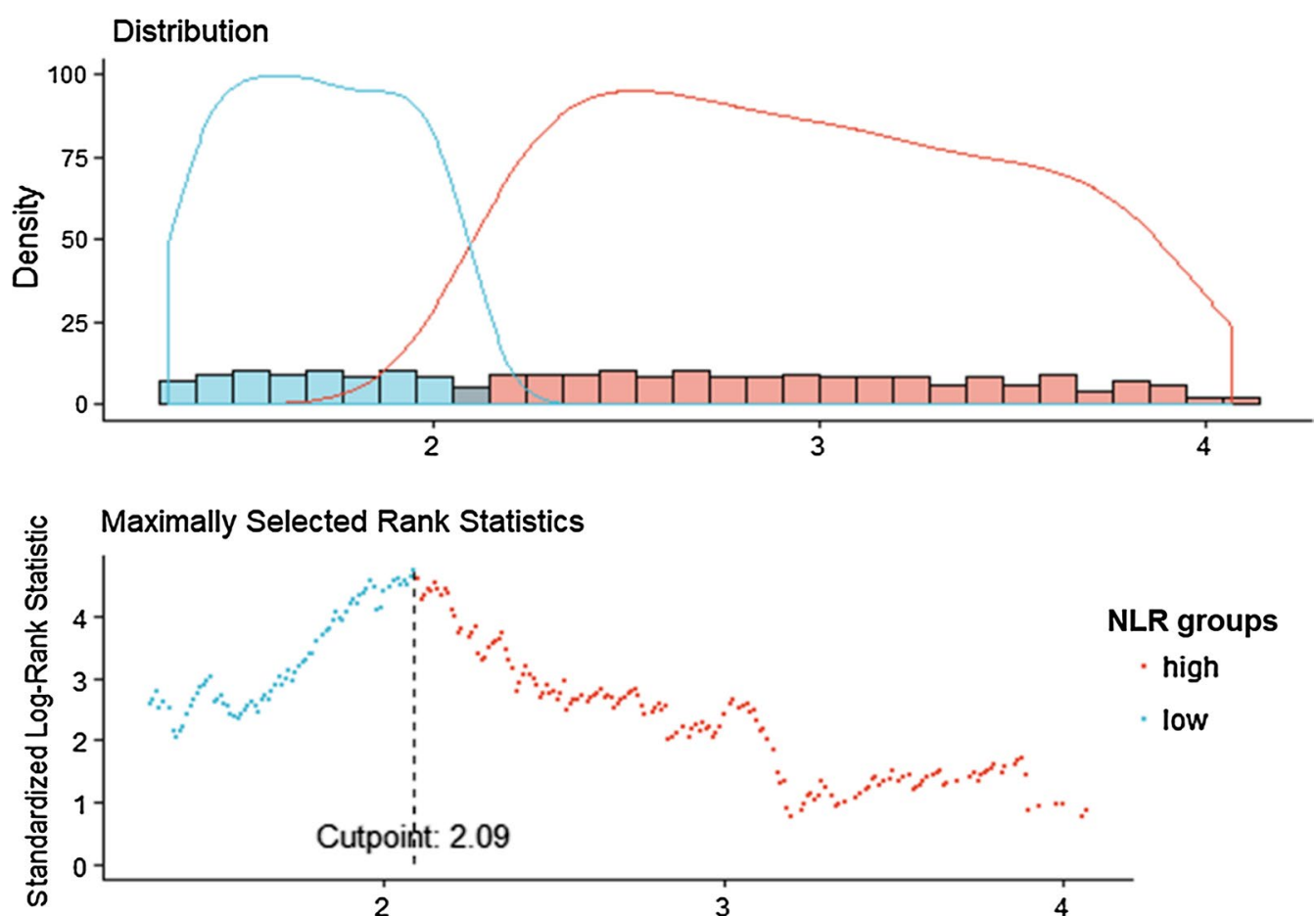

Fig. 1 Maximally selected log-rank statistics for cutoff point of NLR

Table 2 Relationship between NLR levels and ESRD, CVD and all-cause mortality events rates

\begin{tabular}{lcll}
\hline NLR binary & $\begin{array}{l}\text { Number } \\
\text { of events }\end{array}$ & $\begin{array}{l}\text { Events } \\
\text { per 100 } \\
\text { person-years }\end{array}$ & p for log-rank \\
\hline ESRD events & & & \\
$<2.09(\mathrm{~N}=418)$ & $31(7.4 \%)$ & 1.76 & $<0.001$ \\
$\geq 2.09(\mathrm{~N}=520)$ & $92(17.7 \%)$ & 4.27 & \\
Total & $123(17.02 \%)$ & 3.14 & \\
CVD events & & & \\
$<2.09(\mathrm{~N}=418)$ & $19(4.5 \%)$ & 1.03 & \\
$\geq 2.09(\mathrm{~N}=520)$ & $38(7.3 \%)$ & 1.69 & \\
Total & $57(6.1 \%)$ & 1.39 & \\
All-cause mortality & events & & \\
$<2.09(\mathrm{~N}=418)$ & $14(3.4 \%)$ & 0.75 & \\
$\geq 2.09(\mathrm{~N}=520)$ & $29(5.5 \%)$ & 1.26 & \\
Total & $43(4.6 \%)$ & 1.03 & \\
\hline
\end{tabular}

Anti-inflammatory treatment in tubulointerstitial fibrosis of CKD may have renal protective effects [20-23]. An alternative marker of systemic inflammation, c-reactive protein (CRP) has been shown to be a superior prognostic marker if it is persistently elevated [24, 25]. HsCRP was found to be a predictor of mortality and ESRD in pre-dialysis patients with chronic kidney disease [26].
HsCRP, which is synthesized mainly in the liver, only marginally increased even in patients with active infection [24]. Furthermore, it is non-specific and may not fully capture all forms of inflammation [27]. For example, the Multi-Ethnic Study of Atherosclerosis (MESA) demonstrated obesity being independently associated with subclinical atherosclerosis irrespective of hsCRP, with no additive effect when elevated hsCRP was present [28]. What is more, hsCRP is influenced by other factors such as body mass index, weight loss, smoking, active alcohol consumption and diabetes [29]. Similar in our study, we observed that hsCRP was not correlated with the outcome in CKD stage 1-4 patients. hsCRP is thus likely not a good inflammation indicator in CKD patients; other inflammation biomarkers should be investigated to stratify patients with stage 1-4 CKD who are at risk of poor prognosis and to monitor treatment effects.

Studies with relatively small-scale have recently been conducted on whether NLR may be a predictor of CKD progression. The balance between the inflammatory and immune response is also reflected by NLR [7], which shows chronic low-grade inflammation. In addition to a variety of well-known risk factors for CKD progression, this study was aimed to evaluate the relationship between NLR and CKD progression. We used NLR as a surrogate marker of systemic inflammation. NLR is composed of two different complementary immune pathways [30], 


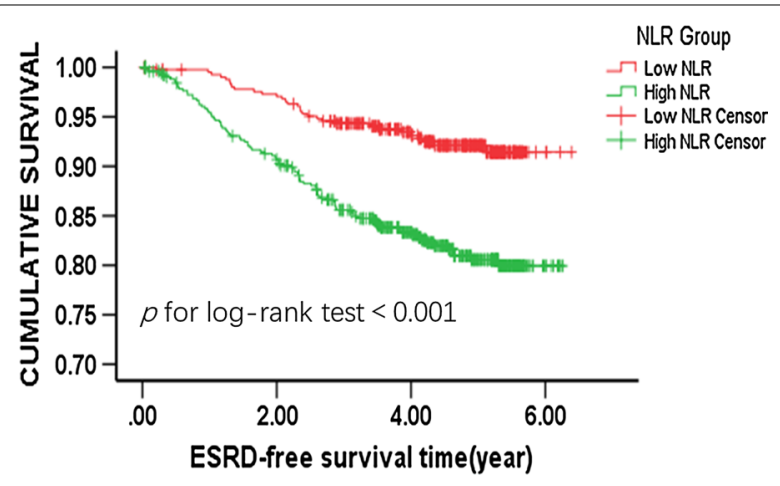

Fig. 2 Kaplan-Meier curve for ESRD events according to binary of NLR

Table 3 Association of NLR with ESRD events among total CKD patients and stratified by stage of CKD

\begin{tabular}{|c|c|c|}
\hline NLR ratio & $\begin{array}{l}\text { Model } 1 \\
\text { HR }(95 \% \mathrm{Cl})\end{array}$ & $\begin{array}{l}\text { Model } 2 \\
\text { HR (95\% Cl) }\end{array}$ \\
\hline \multicolumn{3}{|c|}{ Total CKD patients $(n=938)$} \\
\hline$<2.09$ & 1.00 (Ref) & 1.00 (Ref) \\
\hline$\geq 2.09$ & $2.59(1.72,3.90)$ & $1.16(0.74,1.81)$ \\
\hline $\mathrm{p}$ for trend & $<0.001$ & 0.512 \\
\hline \multicolumn{3}{|c|}{$e G F R \geq 60 \mathrm{~mL} / \min (n=360)$} \\
\hline$<2.09$ & 1.00 (Ref) & 1.00 (Ref) \\
\hline$\geq 2.09$ & $1.77(0.36,8.87)$ & $1.57(0.21,11.98)$ \\
\hline$p$ for trend & 0.485 & 0.663 \\
\hline \multicolumn{3}{|c|}{$30 \leq e G F R<60 \mathrm{~mL} / \min (n=345)$} \\
\hline$<2.09$ & 1.00 (Ref) & 1.00 (Ref) \\
\hline$\geq 2.09$ & $0.98(0.50,1.92)$ & $0.507(0.23,1.11)$ \\
\hline$p$ for trend & 0.95 & 0.089 \\
\hline \multicolumn{3}{|c|}{$15 \leq \mathrm{eGFR}<30 \mathrm{~mL} / \mathrm{min}(\mathrm{n}=233)$} \\
\hline$<2.09$ & 1.00 (Ref) & 1.00 (Ref) \\
\hline$\geq 2.09$ & $2.11(1.18,3.76)$ & $2.124(1.10,4.10)$ \\
\hline$p$ for trend & 0.012 & 0.025 \\
\hline
\end{tabular}

Model 1: Adjusted for age, gender

Model 2: Model $1+$ smoking, drinking, diabetes, hypertension, cardiovascular diseases, hyperuricemia, urine albumin/creatinine ratio, chronic kidney diseasemineral and bone disorder, hemoglobin, hyperlipidaemia, eGFR

and is less likely to be influenced by various physiological conditions such as dehydration. Because some inflammatory cytokines, such as hsCRP, interleukin- 6 and TNF- $\alpha$ are limited to research for nonconventional tests, NLR would be more easily available for clinical practice [31]. NLR displays a prognostic value for proteinuria [32, 33], mortality and RRT [34]. Nevertheless, recent evidence indicates NLR was not an independent predictor of CKD progression in CKD stage 2-4 patients [35]. In our study of a large chinese CKD population for relationship between NLR, ESRD, CVD, or all-cause mortality, our longitudinal study revealed NLR as an independent risk factor of ESRD only in patients with stage 4 CKD after adjusting for classic risk factors of CKD including ACR and eGFR. These patients have severely damaged renal function prior to dialysis [36]; chronic low-grade inflammation will likely promote disease progression towards ESRD in stage 4 CKD patients. In this regard, NLR may not be an independent predictor of CKD progression in patients with CKD at early stages [35]. In renal replacement patients, including hemodialysis and peritoneal dialysis, evidence suggests that NLR predicts CVD and all-cause mortality [7]. Nevertheless, in our study, this relationship could not be demonstrated in pre-dialysis patients. It remains possible that NLR predicts CVD and all-cause mortality only in stage 5 CKD patients.

Our study has several limitations. First, although most well-established risk factors of CKD progression were included in our multivariable regression models, the possibility of residual confounding still exists. Secondly, despite using a large patient cohort organized by multiple centers, risk factor exposures, CVD risk and deaths in some regions were affected by data shortages. Thirdly, the NLR only captured in 938 of 3358 patients, selection bias could not be excluded. Forthly, the cohort has a relatively short duration of follow-up and a limited number of cardiovascular events and death [37], which limited our power to investigate the association between the levels of NLR and CVD and all-cause mortality.

\section{Conclusion}

NLR may independently predict the risk of ESRD in patients with stage 4 CKD. NLR is easily available, which adds valuable prognostic information to the well-established clinical and biochemical prognostic biomarkers. NLR could be used to improve risk-stratification of patients with stage 4 CKD. Future studies are warranted to see whether stage 4 CKD patients with elevated NLR levels will benefit from anti-inflammatory therapies and interventions.

\section{Additional file}

Additional file 1: Table S1. Baseline demographic characteristics of participants of C-STRIDE Study between population with NLR and without NLR. Table S2. Relationship between hsCRP and ESRD, CVD and all-cause mortality events rates.

\section{Abbreviations}

CKD: Chronic kidney disease; NLR: neutrophil-to-lymphocyte ratio; ESRD: end stage of renal disease; CVD: cardiovascular disease; ACR: albumin to creatinine ratio; CKD-MBD: chronic kidney disease-mineral and bone disorder; eGFR: estimated glomerular filtration rate; C-STRIDE: the Chinese Cohort Study of Chronic Kidney Disease; CKD-EPI: the Chronic Kidney Disease Epidemiology 
Collaboration; HRs: hazard ratios; Cls: confidence intervals; SP: serum phosphorus; SCa: serum calcium; MESA: Multi-Ethnic Study of Atherosclerosis.

\section{Authors' contributions}

QJY searched the literature; QJY and JWW analysed the data, interpreted the results and drafted the manuscript. $\mathrm{KH}$ revised the manuscript. HX conceived and design the study, organised and supervised the study, interpreted the results, and revised the manuscript. LXZ and MHZ obtained funding. Other members collected and analysed the data. HX is the guarantor and takes full responsibility for the work as a whole, including the study design, access to data, and the decision to submit and publish the manuscript. All authors read and approved the final manuscript.

\section{Author details}

1 Department of Nephrology, Xiangya Hospital, Central South University, 87 Xiangya Road, Changsha 410008, Hunan, China. ${ }^{2}$ Renal Division, Department of Medicine, Peking University First Hospital, Institute of Nephrology, Peking University, Key Laboratory of Renal Disease, Ministry of Health of China, Key Laboratory of Chronic Kidney Disease Prevention and Treatment (Peking University), Ministry of Education, Beijing 100034, China. ${ }^{3}$ Center for Data Science in Health and Medicine, Peking University, Beijing, China. ${ }^{4}$ Peking-Tsinghua Center for Life Sciences, Beijing, China. ${ }^{5}$ Department of Biostatistics, School of Public Health, University of Michigan, Ann Arbor, MI, USA.

\section{Acknowledgements}

The authors would like to express gratitude to every member of the C-STRIDE group for their collaboration. Dr. Siyi Wanggou (Department of Neurosurgery, Xiangya Hospital, Central South University, Hunan, China) contributes to the finding of NLR cutoff point.

\section{Competing interests}

The authors declare that they have no competing interests.

\section{Availability of data and materials}

All data generated or analysed during this study are included in this published article.

\section{Consent for publication}

Not applicable.

\section{Ethics approval and consent to participate}

The study was approved by the Ethics Committee of Peking University First Hospital and was in adherence with the Declaration of Helsinki.

\section{Funding}

This study was supported by two grants from National Key Research and Development Program (Nos. 2016YFC1305405 and 2011BAl10B01), and a grant by the University of Michigan Health System and Peking University Health Sciences Center Joint Institute for Translational and Clinical Research.

\section{Publisher's Note}

Springer Nature remains neutral with regard to jurisdictional claims in published maps and institutional affiliations.

Received: 21 December 2018 Accepted: 21 February 2019 Published online: 15 March 2019

\section{References}

1. Coresh J, Selvin E, Stevens LA, Manzi J, Kusek JW, Eggers P, Van Lente F, Levey AS. Prevalence of chronic kidney disease in the United States. JAMA. 2007;298(17):2038-47.

2. Zhang L, Wang F, Wang L, Wang W, Liu B, Liu J, Chen M, He Q, Liao Y, Yu X, Chen N, Zhang JE, Hu Z, Liu F, Hong D, Ma L, Liu H, Zhou X, Chen J, Pan L, Chen W, Wang W, Li X, Wang H. Prevalence of chronic kidney disease in China: a cross-sectional survey. Lancet. 2012;379(9818):815-22.

3. Sud M, Naimark DM. Cardiovascular disease in chronic kidney disease in 2015. Curr Opin Nephrol Hypertens. 2016;25(3):203-7.
4. Parrish AR. The cytoskeleton as a novel target for treatment of renal fibrosis. Pharmacol Ther. 2016;166:1-8.

5. Gansevoort RT, Correa-Rotter R, Hemmelgarn BR, Jafar TH, Heerspink HJ, Mann JF, Matsushita K, Wen CP. Chronic kidney disease and cardiovascular risk: epidemiology, mechanisms, and prevention. Lancet. 2013;382(9889):339-52.

6. Solak Y, Yilmaz MI, Sonmez A, Saglam M, Cakir E, Unal HU, Gok M, Caglar K, Oguz Y, Yenicesu M, Karaman M, Ay SA, Gaipov A, Turk S, Vural A, Carrero JJ. Neutrophil to lymphocyte ratio independently predicts cardiovascular events in patients with chronic kidney disease. Clin Exp Nephrol. 2013;17(4):532-40.

7. Reddan DN, Klassen PS, Szczech LA, Coladonato JA, O'Shea S, Owen WF Jr, Lowrie EG. White blood cells as a novel mortality predictor in haemodialysis patients. Nephrol Dial Transplant. 2003;18(6):1167-73.

8. An X, Mao HP, Wei X, Chen JH, Yang X, Li ZB, Yu XQ, Li ZJ. Elevated neutrophil to lymphocyte ratio predicts overall and cardiovascular mortality in maintenance peritoneal dialysis patients. Int Urol Nephrol. 2012:44(5):1521-8.

9. Kocyigit I, Eroglu E, Unal A, Sipahioglu MH, Tokgoz B, Oymak O, Utas C. Role of neutrophil/lymphocyte ratio in prediction of disease progression in patients with stage-4 chronic kidney disease. J Nephrol. 2013;26(2):358-65.

10. Yuan J, Zou XR, Han SP, Cheng H, Wang L, Wang JW, Zhang LX, Zhao $\mathrm{MH}$, Wang XQ, C.S.S. group. Prevalence and risk factors for cardiovascular disease among chronic kidney disease patients: results from the Chinese cohort study of chronic kidney disease (C-STRIDE). BMC Nephrol. 2017;18(1):23.

11. Yan Z, Wang Y, Li S, Wang J, Zhang L, Tan H, Li S, Yang L, Pei H, Zhang L, Wang Y, Duan J, Jiao S, Zhao M, Fu S, G. China National Survey of Chronic Kidney Disease Working. Hypertension control in adults with CKD in China: baseline results from the Chinese Cohort Study of Chronic Kidney Disease (C-STRIDE). Am J Hypertens. 2018;31(4):486-94.

12. Peng Z, Wang J, Yuan Q, Xiao $X, X u H$, Xie $Y$, Wang W, Huang L, Zhong $Y$, Ao X, Zhang L, Zhao M, Tao L, Zhou Q, C.S.s. group. Clinical features and CKD-related quality of life in patients with CKD G3a and CKD G3b in China: results from the Chinese Cohort Study of Chronic Kidney Disease (C-STRIDE). BMC Nephrol. 2017;18(1):311.

13. Stevens LA, Claybon MA, Schmid CH, Chen J, Horio M, Imai E, Nelson RG, Van Deventer M, Wang HY, Zuo L, Zhang YL, Levey AS. Evaluation of the Chronic Kidney Disease Epidemiology Collaboration equation for estimating the glomerular filtration rate in multiple ethnicities. Kidney Int. 2011;79(5):555-62.

14. Bilhorn KR, Luo Y, Lee BT, Wong ND. High-density lipoprotein cholesterol, high-sensitivity C-reactive protein, and cardiovascular disease in United States adults. Am J Cardiol. 2012;110(10):1464-7.

15. Wen CP, Cheng TY, Tsai MK, Chang YC, Chan HT, Tsai SP, Chiang PH, Hsu CC, Sung PK, Hsu YH, Wen SF. All-cause mortality attributable to chronic kidney disease: a prospective cohort study based on 462293 adults in Taiwan. Lancet. 2008;371(9631):2173-82.

16. Go AS, Chertow GM, Fan D, McCulloch CE, Hsu CY. Chronic kidney disease and the risks of death, cardiovascular events, and hospitalization. N Engl J Med. 2004;351(13):1296-305.

17. Wang V, Vilme H, Maciejewski ML, Boulware LE. The economic burden of chronic kidney disease and end-stage renal disease. Semin Nephrol. 2016;36(4):319-30.

18. Liu Y. Cellular and molecular mechanisms of renal fibrosis. Nat Rev Nephrol. 2011;7(12):684-96.

19. Imig JD, Ryan MJ. Immune and inflammatory role in renal disease. Compr Physiol. 2013;3(2):957-76.

20. Zheng L, Zhang J, Yuan X, Tang J, Qiu S, Peng Z, Yuan Q, Xie Y, Mei W, Tang $Y$, Meng J, Hu G, Tao L. Fluorofenidone attenuates interleukin-1 beta production by interacting with NLRP3 inflammasome in unilateral ureteral obstruction. Nephrology. 2018;23(6):573-84.

21. Zhang J, Zheng L, Yuan X, Liu C, Yuan Q, Xie F, Qiu S, Peng Z, Tang Y, Meng J, Qin J, Hu G, Tao L. Mefunidone ameliorates renal inflammation and tubulointerstitial fibrosis via suppression of IKKbeta phosphorylation. Int J Biochem Cell Biol. 2016;80:109-18.

22. Liu C, Mei W, Tang J, Yuan Q, Huang L, Lu M, Wu L, Peng Z, Meng J, Yang $H$, Shen $H$, Lv B, Hu G, Tao L. Mefunidone attenuates tubulointerstitial fibrosis in a rat model of unilateral ureteral obstruction. PLOS ONE. 2015;10(6):e0129283. 
23. Hu C, Yang M, Zhu X, Gao P, Yang S, Han Y, Chen X, Xiao L, Yuan S, Liu F, Kanwar YS, Sun L. Effects of omega-3 fatty acids on markers of inflammation in patients with chronic kidney disease: a controversial issue. Ther Apher Dial. 2018;22(2):124-32.

24. Cervoni JP, Thevenot T, Weil D, Muel E, Barbot O, Sheppard F, Monnet E, Di Martino V. C-reactive protein predicts short-term mortality in patients with cirrhosis. J Hepatol. 2012;56(6):1299-304.

25. Mo X, Pi L, Yang J, Xiang Z, Tang A. Serum indoleamine 2,3-dioxygenase and kynurenine aminotransferase enzyme activity in patients with ischemic stroke. J Clin Neurosci. 2014;21(3):482-6.

26. Jagadeswaran D, Indhumathi E, Hemamalini AJ, Sivakumar V, Soundararajan $\mathrm{P}$, Jayakumar $\mathrm{M}$. Inflammation and nutritional status assessment by malnutrition inflammation score and its outcome in pre-dialysis chronic kidney disease patients. Clin Nutr. 2019;38(1):341-7.

27. Ritchie SC, Wurtz P, Nath AP, Abraham G, Havulinna AS, Fearnley LG, Sarin AP, Kangas AJ, Soininen P, Aalto K, Seppala I, Raitoharju E, Salmi M, Maksimow M, Mannisto S, Kahonen M, Juonala M, Ripatti S, Lehtimaki T, Jalkanen S, Perola M, Raitakari O, Salomaa V, Ala-Korpela M, Kettunen J, Inouye M. The biomarker GlycA is associated with chronic inflammation and predicts long-term risk of severe infection. Cell Syst. 2015;1(4):293-301.

28. Blaha MJ, Rivera JJ, Budoff MJ, Blankstein R, Agatston A, O'Leary DH, Cushman M, Lakoski S, Criqui MH, Szklo M, Blumenthal RS, Nasir K. Association between obesity, high-sensitivity $C$-reactive protein $\geq 2 \mathrm{mg} / \mathrm{L}$, and subclinical atherosclerosis: implications of JUPITER from the Multi-Ethnic Study of Atherosclerosis. Arterioscler Thromb Vasc Biol. 2011;31(6):1430-8.

29. Pearson TA, Mensah GA, Alexander RW, Anderson JL, Cannon RO 3rd, Criqui M, Fadl YY, Fortmann SP, Hong Y, Myers GL, Rifai N, Smith SC Jr, Taubert K, Tracy RP, Vinicor F, C. Centers for Disease, Prevention, A. American Heart. Markers of inflammation and cardiovascular disease: application to clinical and public health practice: a statement for healthcare professionals from the Centers for Disease Control and Prevention and the American Heart Association. Circulation. 2003;107(3):499-511.

30. Balta S, Ozturk C, Balta I, Demirkol S, Demir M, Celik T, Iyisoy A. The neutrophil-lymphocyte ratio and inflammation. Angiology. 2016;67(3):298-9.

31. Kuo YT, Wang YY, Lin SY, Chang WD. Age and sex differences in the relationship between neutrophil-to-lymphocyte ratio and chronic kidney disease among an adult population in Taiwan. Clin Chim Acta. 2018;486:98-103.

32. Binnetoglu E, Sengul E, Halhalli G, Dindar S, Sen H. Is neutrophil lymphocyte ratio an indicator for proteinuria in chronic kidney disease? J Clin Lab Anal. 2014;28(6):487-92

33. Kutlugun AA, Ebinc FA, Ozturk MT, Efe FK, Karadag I, Eser M, Unsal O, Karakaya S. Association of neutrophil-to-lymphocyte ratio and microalbuminuria in patients with normal eGFR. Rom J Intern Med. 2018;56(1):21-6.

34. Tatar E, Mirili C, Isikyakar T, Yaprak M, Guvercin G, Ozay E, Asci G. The association of neutrophil/lymphocyte ratio and platelet/lymphocyte ratio with clinical outcomes in geriatric patients with stage 3-5 chronic kidney disease. Acta Clin Belg. 2016;71(4):221-6.

35. Altunoren O, Akkus G, Sezal DT, Ciftcioglu M, Guzel FB, Isiktas S, Torun Gl, Uyan M, Sokmen MF, Sevim HA, Sarisik FN, Senel ME, Erken E, Gungor O. Does neutrophyl to lymphocyte ratio really predict chronic kidney disease progression? Int Urol Nephrol. 2019;51(1):129-37.

36. Feng M, Lv J, Huang FT, Liang PF, Fu S, Zeng YC, Tang Y, Xu AP. Predictors of vitamin D deficiency in predialysis patients with stage 3-5 chronic kidney diseases in Southern China. Niger J Clin Pract. 2017;20(10):1309-15.

37. Lv L, Wang J, Gao B, Wu L, Wang F, Cui Z, He K, Zhang L, Chen M, Zhao $\mathrm{MH}$. Serum uromodulin and progression of kidney disease in patients with chronic kidney disease. J Transl Med. 2018;16(1):316.
Ready to submit your research? Choose BMC and benefit from:

- fast, convenient online submission

- thorough peer review by experienced researchers in your field

- rapid publication on acceptance

- support for research data, including large and complex data types

- gold Open Access which fosters wider collaboration and increased citations

- maximum visibility for your research: over 100M website views per year

At BMC, research is always in progress.

Learn more biomedcentral.com/submissions 